\title{
Por uma nova abordagem de leitura bíblica: uma contraproposta à hermenêutica fundamentalista a partir da teologia de A. T. Queiruga
}

\author{
For a new approach to biblical reading: \\ a counterproposal to fundamentalist hermeneutics from the theology of A. T. Queiruga
}

\author{
Rodrigo Batista Alberto* \\ Alessandro Bartz** \\ Marcio Cappelli Alo Lopes ${ }^{* * *}$
}

\begin{abstract}
Resumo
Por uma nova abordagem de leitura bíblica: Uma contraproposta à hermenêutica fundamentalista a partir da teologia de A. T. Queiruga ocupa-se com a necessidade apresentada pelos tempos pós-modernos no que tange à revisão da hermenêutica adotada pelas igrejas protestantes. Este artigo faz uso do método baseado na pesquisa bibliográfica e visa apontar um caminho que ajude a superar o modelo fundamentalista. A reflexão orbita sobre uma questão básica para o artigo: pode-se ressignificar a compreensão literal dos textos bíblicos sem se desviar dos princípios do Reino Deus anunciados por Jesus? Ou seja, o foco do trabalho está em verificar se a riqueza do texto perpassa sua recepção literal e, apesar de introduzir um certo incômodo ao entendimento comum, isso não desonraria sua mensagem. Para tal, pretende-se contrapor os pontos substanciais do movimento fundamentalista com a abordagem do teólogo Queiruga, sobretudo no primeiro capítulo do livro Do terror de Isaac ao Abbá de Jesus.
\end{abstract}

\section{Palavras-chave}

Fundamentalismo. Queiruga. Hermenêutica.

\begin{abstract}
For a new approach to biblical reading: A counterproposal to fundamentalist hermeneutics from the theology of A. T. Queiruga deals with the need presented by postmodern times in regard to the revision of
\end{abstract}

[Texto recebido em junho de 2017 e aceito em janeiro de 2018, com base na avaliação cega por pares realizada por pareceristas ad hoc]

* Pós-Graduando em Teologia Bíblica e Sistemática Pastoral (FABAT). Bacharel em Teologia (Centro Universitário Cenecista de Osório). Bacharel em Engenharia Naval e Oceânica (UFRJ). E-mail: rodbat@hotmail.com

** Doutor em Teologia (Faculdades EST). Professor do Centro Universitário Cenecista de Osório. E-mail: alessandro_bartz@yahoo.com.br

*** Doutor em Teologia (PUC-Rio). Mestre em Teologia (PUC-Rio). Graduação em Teologia (STBSB). Professor da Faculdade Batista do Rio de Janeiro. E-mail: alocappelli@gmail.com 


\begin{abstract}
the hermeneutics adopted by Protestant churches. This article makes use of the method based on bibliographical research and aims to point out a path that helps to overcome the fundamentalist model. The reflection orbits on a basic question for the article: can one resignify the literal understanding of the biblical texts without deviating from the principles of the God's Kingdom announced by Jesus? That is to say, the focus of the work is to verify if the richness goes beyond its literal reception and, although introducing a discomforting to the common understanding, it would not dishonor its message. In order to do so, it is intended to counter the substantial points of the fundamentalist movement with the approach of the theologian Queiruga, especially in the first chapter of the book "Do Terror de Issac ao Abbá de Jesus".
\end{abstract}

\title{
Keywords
}

Fundamentalism. Queiruga. Hermeneutics.

\section{Introdução}

A temática fundamentalista ganhou muito destaque no século XXI, especialmente após o emblemático ataque às Torres Gêmeas, em 11 de setembro de 2001. Seu emprego tem perpassado o universo religioso protestante, dado que tem sido utilizado para categorizar os sucessivos atos terroristas ocorridos nos últimos anos em inúmeras cidades do mundo. Em vista disso, este é um fenômeno de extrema relevância a ser estudado em razão de permear o dia a dia da sociedade.

É possível apresentar uma contraproposta à hermenêutica fundamentalista para o cenário protestante brasileiro? Se sim, há ainda outra pergunta: é possível fazê-la de forma comprometida com o Pai de amor apresentado por Jesus Cristo? Para tentar responder a essas perguntas, o caminho a ser percorrido é o do diálogo entre os pontos principais do fundamentalismo e a teologia de A. T. Queiruga, contida em Do Terror de Isaac ao Abbá de Jesus (2001).

A proposta dessa reflexão é expor, num primeiro momento, os elementos que motivaram o desenvolvimento da hermenêutica fundamentalista, tal qual a descrição dos seus pilares de sustentação. Em seguida, será apresentada a teologia de Queiruga, contida no primeiro capítulo da obra mencionada acima. Por fim, pretende-se articular alguns elementos indispensáveis a serem trabalhados pela teologia contemporânea, mormente, acerca da atualização da mensagem cristã.

\section{Fundamentalismo: conceituação e história}

Atualmente, o termo fundamentalismo tem sido aplicado em diversas esferas; basicamente é utilizado para qualificar uma conduta rígida, ideológica, que não se abre para diálogo e críticas, muitas vezes expressadas de forma violenta. Neste contexto, é importante delimitar o sentido no qual se pretende estudar o termo, pois além de plural, 
tornou-se também uma palavra pejorativa. Este presente trabalho irá restringir o sentido ao âmbito religioso e dentro do domínio protestante.

Boff conceitua o movimento da seguinte maneira:

Não é uma doutrina. Mas uma forma de interpretar e viver a doutrina. É assumir a letra das doutrinas e normas sem cuidar de seu espírito e de sua inserção no processo sempre cambiante da história, que obriga a contínuas interpretações e atualizações, exatamente para manter sua verdade essencial. Fundamentalismo representa a atitude daquele que confere caráter absoluto ao seu ponto de vista. ${ }^{1}$

Reconhecer a religião como parte integrante de um processo histórico é o primeiro passo para discernir sua conjuntura no âmbito atual. Inegavelmente, com o passar dos anos, a fé absorveu diferentes visões de mundo, incorporou peculiaridades de determinadas épocas e, desta forma, moldou sua identidade. Para melhor percepção do fenômeno "fundamentalismo religioso", é vital conhecer o ambiente que precedeu seu nascimento. Nesse sentido, a expansão da teologia liberal, ${ }^{2}$ entre o final do século XIX e começo do século XX, foi decisiva.

A teologia liberal trouxe a crítica para o universo religioso, principalmente fazendo uso do método histórico-crítico na interpretação dos textos bíblicos, o qual acaba por investigar o texto de forma científica, ou seja, procura saber se os fatos ocorreram da exata maneira que estão apresentados, o que acabou por relativizar muitos conceitos que estavam enraizados na vida dos fiéis.

Os pontos elementares do método histórico-crítico são: ${ }^{3}$ a) Crítica Textual: Reconstrução do texto originário; b) Crítica das Fontes: Identificação das fontes escritas que contribuíram para a formação do texto; c) Crítica dos Gêneros Literários: Comparação entre textos estruturalmente idênticos ou análogos e, com base nas coincidências estruturais, inseri-lo em um grupo de textos; d) Método Comparativo: Confrontar certo sistema religioso com outro sistema para descobrir semelhanças e diferenças; e) História

1 BOFF, L. Fundamentalismo, terrorismo, religião e paz: desafio para o século XXI. Petrópolis: Vozes, 2009. p. 49.

2 Mais detalhes encontram-se em: PANASIEWICZ, R. Fundamentalismo Religioso: história e presença no cristianismo. In: X Simpósio da Associação Brasileira da História das Religiões: Migrações e Imigrações das Religiões, 2008. p. 5. No universo protestante europeu, no final do século XIX e começo do século XX, começa a despontar uma teologia que quer entrar em diálogo com a modernidade. Sobretudo teólogos como Albert Ritschl, Otto Pfleiderer, Adolf von Harnack e Ernst Troeltsch irão desenvolver a teologia liberal. Esse liberalismo teológico parte do seguinte postulado fundamental: "o cristianismo deve reconciliar-se com o mundo moderno, isto é, com o seu naturalismo científico, com o seu racionalismo moral, com a sua democracia política. O cristianismo deve assimilar todo o valor positivo da modernidade, o que o tornará mais puro, mais autêntico". Nesta busca de tornar o cristianismo moderno, irão usufruir de todo racionalismo possível para interpretá-lo de forma que passe a dizer algo significativo, não contraditório e verdadeiro a este novo homem e a esta nova mulher moderna.

3 VECCHIA, F. Dalla. Método histórico-crítico. In: VV.AA. Dicionário teológico enciclopédico. São Paulo: Loyola, 2003. p. 489. 
das tradições: Identifica as tradições subjacentes ao texto e estuda a história da transmissão destas; f) História da Redação: Parte do texto em sua relação final para patentear o objetivo perseguido, a posição assumida ou a orientação teológica do redator final.

Servindo como pano de fundo para o crescimento da teologia liberal, iniciando no século XVII, tem-se a emersão de uma consciência autônoma, histórica e crítica, período que se convencionou chamar de Modernidade. ${ }^{4}$ A evolução do conhecimento teórico sobre as ciências naturais e humanas levou, na segunda metade do século XIX, a uma crise cultural e religiosa. ${ }^{5}$ Uma visão bem esclarecedora sobre a modernidade, cujas características motivaram o nascimento do movimento fundamentalista, é apresentada por Panasiewicz do seguinte modo:

Enquanto a modernidade é uma reação à estrutura de organização medieval, centrada na autoridade, ela centra-se na razão humana e na ciência, carregando a bandeira da autonomia do sujeito histórico. Em contrapartida, o fundamentalismo religioso é um movimento crítico às inovações trazidas pela modernidade a partir de uma narrativa sagrada e de um monopólio de interpretação balizado pela religião. ${ }^{6}$

Dreher destaca que:

No fundamentalismo temos, em primeiro lugar, oposição e reação contra transformações da religião, determinadas pela Modernidade. $\mathrm{O}$ fundamentalista quer defender sua verdade religiosa, que ele vê ameaçada pelos "poderes" da Modernidade, designados de pluralismo, relativismo, historicismo e destruição de autoridades.7

Para os teólogos liberais, uma harmonização entre o cristianismo e a modernidade era fundamental; caso contrário, à fé cristã se tornaria uma religião irrelevante e sem sentido aos tempos modernos. Dentre os principais pilares defendidos por eles, destacamse: a) Abertura para a teoria da evolução de Charles Darwin; b) Uso da crítica histórica e textual na interpretação da Bíblia; c) A Bíblia é considerada como produção humana, a qual reflete a experiência religiosa do povo ao longo de muitos anos; d) Receptivo à teoria da revelação progressiva; e) Adoção da influência cultural e religiosa dos povos vizinhos

4 BALEEIRO, C. A. S. A Dinâmica dos Fundamentalismos: modernidade e tradição. In: SOUZA, Sandra Duarte de. (Org.). Fundamentalismos religiosos contemporâneos. São Paulo: Fonte, 2013. p. 22. Jean-Louis Schlegel apresenta seis características da modernidade e de que maneira elas estão ligadas ao surgimento dos grupos fundamentalistas. As características apresentadas por ele são: a autonomia, a democracia, a secularização, os direitos humanos, o desenvolvimento técnico e científico, a historicidade e a crise da razão.

5 LIMA, M. L. C. Fundamentalismo: Escritura e Teologia entre fé e razão. Atualidade Teológica, ano XIII, n. 33, set./dez. 2009. p. 2.

6 PANASIEWICZ, 2008, p. 2.

7 DREHER, M. N. Fundamentalismo. São Leopoldo: Sinodal, 2006. p. 82. 
de Israel na construção de sua identidade religiosa; f) Revisão dos dogmas e doutrinas da igreja, mediante a experiência religiosa do indivíduo.

Os pontos acima foram recebidos com espanto pela ala conservadora das igrejas em todos os Estados Unidos e serviu de combustível para movimentos reacionários. ${ }^{8}$ Esse grupo tinha o receio que esse pensamento liberal colocasse em risco tanto o cristianismo quanto a própria civilização humana. ${ }^{9}$

Dentro do universo protestante, o berço do fundamentalismo se deu nos Estados Unidos, por meio do trabalho de pregadores e teólogos que atuavam na Universidade de Princeton. ${ }^{10}$ Entre 1909 e 1915, foram publicados uma série de doze pequenos livros denominados de The Fundamentals: a Testimonium to the Truth (Os Fundamentais: um Testemunho em favor da Verdade). A publicação recebeu o financiamento de Lyman e Milton Stewart, dois magnatas do petróleo. Cada um dos doze livretos teve uma tiragem de três milhões de exemplares com livre distribuição para pastores, professores e estudantes de teologia. Apesar de ser considerado como um dos marcos do fundamentalismo nos Estados Unidos, a publicação não despertou muito interesse na época. ${ }^{11}$

Dreher resume nas seguintes palavras:

Do título dessa série saiu o nome de um movimento, formado no último terço do século XIX por grupos de cristãos conservadores evangelicais. Esse foi crescendo, principalmente graças ao suporte financeiro de leigos bem estabelecidos. Temos aqui o nascimento do fundamentalismo protestante, que determinará os Estados Unidos da América do Norte e que, em pouco tempo, começará a ser exportado para outros continentes e países. ${ }^{12}$

Nos anos seguintes, o movimento obteve um grande crescimento, principalmente com a realização de conferências e investimento em mídias de massa como rádio e televisão. O Brasil, como campo missionário muito fértil, foi grande alvo de cruzadas evangelísticas que expandiram essa abordagem mediante a abertura de seminários, escolas, produção literária e séries de pregações. ${ }^{13}$ Dentre as doutrinas fundamentais estruturantes do pensamento fundamentalista original, destacam-se: a) Inerrância da

8 PANASIEWICZ, 2008, p. 5. Um evento marcante ocorreu em 1895, uma conferência bíblica realizada em Nicarágua na qual o grupo ali presente estabeleceu premissas que posteriormente serviram como base para o fundamentalismo.

9 CARVALHO, 2013, p. 53.

10 BOFF, 2009, p. 11.

11 CARVALHO, 2013, p. 58.

12 DREHER, 2006, p. 81.

13 BOFF, 2009, p. 15. O fundamentalismo protestante ganhou relevância social nos Estados Unidos a partir dos anos 1950 com as "Electronic Church". Pregadores nacionalmente famosos usaram o rádio e a televisão em cadeia para suas pregações e campanhas conservadoras. Sob o Presidente Ronald Reagan, essas igrejas eletrônicas significaram um fator público determinante, favorecerem medidas restritivas em muitos campos da vida pública, particularmente com referência aos imigrados e à assistência aos pobres. 
Escritura; b) Divindade de Cristo; c) Nascimento virginal de Cristo; d) A remissão dos pecados da humanidade pela crucificação de Jesus; e) A ressurreição de Jesus como um fato histórico.

Diante dessa abordagem, os avanços científicos são questionados e o confronto clássico com a comunidade científica se dá na teoria da evolução. ${ }^{14}$ Os fundamentalistas negam a veracidade de qualquer tese que contrarie o criacionismo apresentado pelo livro do Gênesis. Segundo Boff, para o fundamentalista, a criação se realizou mesmo em sete dias, o ser humano feito literalmente de barro e Eva tirada da costela física de Adão. ${ }^{15}$

Até mesmo em questões que não sejam crucias para o entendimento da origem da vida na Terra ou fundamentais para a conduta moral humana, como por exemplo a autoria dos livros canônicos, o assunto é veementemente rebatido à luz da leitura literal dos textos bíblicos, simplesmente pelo livro ter o nome de determinada pessoa. É quase uma ofensa à santidade dos textos propor à discussão que possivelmente o livro tenha levado o nome de determinada pessoa para que tivesse maior força, reconhecimento e fácil circulação dentro das comunidades da época.

Boff é bastante profundo em sua análise sobre o tema:

Em nome deste literalismo, estes fiéis opunham-se às interpretações da assim chamada Teologia Liberal, que usava, e usa ainda hoje, os métodos histórico-críticos e hermenêuticos para interpretar textos escritos milhares de anos atrás. Segundo estes métodos, a história e as palavras não ficam congeladas no passado, mas mudam de sentido ou ganham novas ressonâncias de acordo com a mudança dos contextos históricos. Por isso precisam ser interpretadas para terem resgatado seu sentido original. $\mathrm{Na}$ concepção dos fundamentalistas, esse procedimento, considerado natural pelo simples bom-senso, é ofensivo a Deus. ${ }^{16}$

É inconteste que a hermenêutica adotada pelo fiel constrói sua visão de mundo, molda seus hábitos e valores morais. Para o fundamentalista, portanto, a verdade está na letra, o texto deve ser lido e entendido conforme está escrito, sem margens para interpretações ou críticas. ${ }^{17}$ Em geral, essa postura promove um sentimento de

14 DREHER, 2006, p. 85. No Estado norte-americano do Tennessee, um professor de Biologia chamado Scopes teve que se defender em juízo da acusação por parte de fundamentalistas de que transmitira a seus alunos a teoria da evolução das espécies de Charles Darwin. Bem ao estilo fundamentalista, Scopes acabou sendo advertido pelo tribunal. O caso de Scopes mostra que, para o fundamentalismo, a verdade religiosa é pressuposto para a ação política. Seu alvo é a sociedade perfeita. A sociedade perfeita só se estabelece quando todos se submetem à verdade religiosa, assim como foi ditada pelo Espírito Santo a determinadas pessoas e fixada nas páginas inerrantes, incapazes de erro, do texto bíblico.

15 BOFF, 2009, p. 12.

16 BOFF, 2009, p. 11.

17 DREHER, 2006, p. 93. O fundamentalista experimenta a sociedade que o cerca em decadência moral e anômica, sem lei e sem normas. Por isso, a comunidade fundamentalista concede-lhe descanso e segurança em razão de suas regras severas e normativas. Assim, o fundamentalismo torna-se convidativo e atraente para uma parcela significativa da humanidade, pois oferece segurança em meio a verdades que 
superioridade perante as outras religiões, pois apenas os fundamentalistas teriam o correto entendimento da vontade divina, propiciando a promoção da intolerância e o desmerecimento das outras compreensões.

Além do mais, muitas doutrinas seguidas pelas comunidades fundamentalistas baseiam-se nas interpretações trazidas por seu líder espiritual a cada semana. Estas devem ser aceitas como se viessem de Deus, portanto, não são passíveis de questionamento. Qualquer crítica é imediatamente rejeitada e rebatida com textos bíblicos, mesmo que desvirtuados de seus contextos (literário, situacional, cultural). ${ }^{18}$ Em geral, utilizam muito as expressões “a Bíblia diz" ou “está na Bíblia”, que tem por objetivo dar autoridade ao trecho lido e fazer dele a vontade divina para os ouvintes.

Torna-se muito difícil, senão impossível, dialogar com um fundamentalista a respeito do processo de formação da Bíblia, apresentar que ela contém um compêndio de tradição oral, gêneros literários, marcas de inúmeras situações históricas, influência de povos vizinhos, trazem um grande desconforto e acaloram o debate.

Conforme apontado pelo teólogo Arens, "o fundamentalista se move na base de um conjunto de textos que considera chaves, e subordina ou "esquece" os demais, especialmente palavras que aparecem na boca de Deus ou de algum profeta". ${ }^{19}$

Rubem Alves levanta a seguinte pergunta:

O fundamentalismo é, talvez, a grande tentação que nos assalta. [...] Qual é a pessoa que não anseia por trocar seus palpites por visões da realidade, suas dúvidas por certezas, sua provisoriedade por eternidade, suas inquietações e incompletude por paz e realização?20

Contudo, a maior dificuldade não está na adoção de verdades fundamentais, dado que as igrejas da Reforma já possuíam tal características, mas sim no repúdio pelo desenvolvimento das ciências humanas, (arqueologia, história, filosofia...), teorias literárias e hermenêuticas. ${ }^{21}$ Desse modo, ante os fatos apontados, torna-se substancial a busca por alternativas frente à hermenêutica fundamentalista. À vista disso, cabe ao presente estudo explorar uma construção teórica que sinalize para um caminho de mudança.

se desvanecem, porto seguro em meio a pluralidades, relativizações e dissoluções das certezas antigas. $\mathrm{O}$ fundamentalismo torna-se instrumento de verificação para uma Modernidade que laborou em equívoco e que produziu monstros em nome de uma outra divindade, que não é Javé, nem o Pai de Jesus, nem Alá, mas o mercado. Nosso mundo busca desesperadamente uma nova ordem de valores.

18 ARENS, E. A Bíblia sem mitos: uma introdução crítica. São Paulo: Paulus, 2007. p. 384.

19 ARENS, 2007, p. 384.

20 ALVES, R. O Enigma da Religião. Petrópolis: Vozes, 1975. p. 117.

21 LIMA, 2009, p. 19. 


\section{A teologia de Queiruga em contraproposta com a hermenêutica fundamentalista}

A seguir, com o auxílio da teologia exposta por Queiruga, objetiva-se expor um modelo que ampare uma estrutura de pensamento capaz de propor mudanças aos pilares adotados pelo fundamentalismo.

Queiruga é um teólogo, filósofo e pensador galego formado no seminário da Universidade de Santiago de Compostela, possui inúmeras obras publicadas no Brasil, entre elas: Recuperar a criação (1999), A revelação de Deus na realização humana (1995), Recuperar a salvação (1999), O que queremos dizer quando dizemos inferno? (1997), Um Deus para hoje (1998) e Fim do cristianismo pré-moderno (2003). Possui grande influência no cenário teológico brasileiro e suas obras têm servido de fonte para um grande número de trabalhos acadêmicos. A proposta a seguir é apresentar algumas contribuições teológicas importantes que podem ajudar a superar o modelo fundamentalista, sobretudo a partir do primeiro capítulo do livro Do terror de Issac ao Abbá de Jesus (2001).

Muito do simbolismo e referências utilizadas no texto bíblico, se trazidas de forma literal, perdem o sentido dentro da cultura atual. Fazer uma correlação direta pode ser incoerente, distorcer a intenção original do autor ou até mesmo ser ofensiva. Certamente será alvo de processo jurídico quem ordenar que as mulheres permaneçam caladas ao longo do culto (1 Coríntios 14.34-35). Será que é de fato um ato advindo de Deus o extermínio de toda uma comunidade? Isso é até inaceitável pensando no Pai de amor apresentado por Jesus.

A riqueza ali contida é inestimável, um grande misto de sabedoria, relatos históricos e experiências de fé que perpassaram centenas de gerações desde sua elaboração original. Embora, conforme Queiruga, uma atualização desse tesouro faz-se necessária para que fale ao tempo presente. No seu dizer:

Esse tesouro, porém, chega até nós proveniente de uma cultura muito anterior, nascida em uma sensibilidade milenarmente distinta e responde a perguntas ou necessidades concretas que já não são, de forma alguma, as nossas. $^{22}$

Para Queiruga, não existe redução ou profanação do texto quando este é aberto à crítica e atualização. Pelo contrário, ressalta ainda mais sua profundidade, vivifica seus relatos e livra-o de ser refém de uma interpretação que pretenda dominar seu sentido. Como ele mesmo destaca:

Pelo contrário, respeitar a letra enquanto situada em seu tempo e, contudo, negá-la hoje, ultrapassando-a na direção do significado profundo que nela se anunciava, pode ser, em um primeiro momento duro e até mesmo

22 QUEIRUGA, A. T. Do Terror de Isaac ao Abbá de Jesus. São Paulo: Paulinas, 2001. p. 13. 
"escandaloso"; todavia, em uma visão mais ampla, acaba convertendo-se na única forma de mantê-la como fonte viva, com valor atual. ${ }^{23}$

Percebe-se a preocupação do autor em defender que o texto esteja livre para que possa estar vivo para a atualidade, trazendo reflexão e significado ao leitor, mas dentro do contexto no qual vive. Afinal, agarrar-se à letra não é o melhor modo de ser fiel ao espírito. ${ }^{24}$

Não estudar e não ter profundidade de conhecimento faz o fiel dependente e sujeito a acreditar em tudo o que lhe é dito, deixa-o sem argumentação e incapaz de embasar seu ponto de vista durante um diálogo. A postura acrítica, historicamente, foi estimulada quando da dominação de uma pequena elite intelectual sobre um grupo. No universo protestante, instaurou-se um peso pecaminoso sobre o estudo crítico dos textos bíblicos, uma vez que "a crítica pode parecer profanação e o empenho na atualização pode ser interpretado como infidelidade ou abandono" ${ }^{25}$

Ainda, segundo Queiruga:

A consequência inevitável é, então, o fundamentalismo ou o positivismo bíblico, isto é, o fato de ler as palavras do livro sagrado como se fossem um "ditado" literal divino, que devem ser tomadas ao pé da letra, embora falem de biologia ou de astronomia, embora atribuam a Deus a peste, o assassinato ou a guerra. ${ }^{26}$

Essa abordagem literal acaba sendo extremamente contraditória, pois muitas condutas morais são defendidas apenas pelo fato de "estar na Bíblia", sem qualquer outra explicação, enquanto que outras também ali contidas são negadas. Essa fragmentação geralmente é tendenciosa. Por exemplo, é comum ocorrer a seleção de versículos para uma leitura responsiva durante uma liturgia, onde são selecionados trechos de cânticos de vitória e promessas espalhados por toda a Bíblia e lê-se de forma sequencial. Interessante perceber, que estes mesmos versículos, por exemplo, podem fazer parte de relatos de guerra e as passagens imediatamente acima ou abaixo são ignoradas, pois não seriam "motivadoras".

Por conta de sua maravilhosa poesia, um exemplo desse uso é o livro dos Salmos, muitos de seus versículos são utilizados para rechear as caixinhas de promessas, adesivos e afins; entretanto, não se vê sendo utilizado como referência, por exemplo, Salmos 137.9: "Feliz aquele que pegar em teus filhos e der com eles nas pedras". Portanto, percebe-se uma seletividade e contradição na hermenêutica fundamentalista, uma vez que com o

\footnotetext{
QUEIRUGA, 2001, p. 14.

QUEIRUGA, 2001, p. 17.

QUEIRUGA, 2001, p. 22.

QUEIRUGA, 2001, p. 30.
} 
mesmo desconhecimento que se escolhem alguns trechos, outros são desconsiderados. Consoante à concepção de Queiruga,

As consequências são inevitáveis: a Bíblia acaba se transformando em um livro estranho, contraditório, em que o sublime situa-se no mesmo nível que o horrível, e no qual tesouros de infinita profundidade religiosa são recobertos por absurdos conceituais, surgidos da interpretação científica do mítico e do simbólico, ou simplesmente do fato de tomar-se por revelação divina aquilo que não passa de mero reflexo cultura de um tempo passado. E o dogma é solidificado em conceitos arcaicos, incapazes de falar hoje e dando lugar a interpretações que, situadas em um contexto radicalmente renovado e diferente do original, nem convencem a inteligência, nem podem mover a vida. ${ }^{27}$

Os tempos atuais urgem por uma revisão nesse fixismo. A pós-modernidade formou uma sociedade extremamente questionadora e que clama por coerência. É uma tarefa delicada, pois afeta os valores de fé. É como mexer num campo minado. Quando a comunidade científica divulgou que Plutão ${ }^{28}$ não seria mais considerado como um planeta, isso certamente causou surpresa para muitas pessoas. Quantos não cresceram tendo que memorizar tal informação para alguma prova escolar? Pois bem, apesar de nova, essa mudança não abala o mais profundo ser humano, sua esperança, valores ou crenças, como ocorre quando se confronta um dogma religioso.

É certo que a modernidade abalou as estruturas do pensamento religioso de uma maneira nunca vista antes, incomodou uma liderança que determinou por séculos o rumo do saber teológico e trouxe muitos questionamentos para toda a sociedade. Contudo, por outra ótica, todo esse movimento abriu portas para o novo, pois "as mudanças profundas não são uma resposta de uns poucos, mas a uma necessidade do tempo" e "essa mudança não tem por que anular o passado; o que se exige é compreendê-lo e vivê-lo de outra maneira". 29

A questão não está em negar o passado, pelo contrário, é ressignificá-lo para que tenha o mesmo impacto de quando ocorrido originalmente, é trazer para o tempo presente seus princípios originários. Queiruga apresenta que a acomodação, assim como a resistência à mudança e a tentativa de defesa com meros arranjos que não vão à raiz, é um grande perigo, pois é mais invisível e transparente. ${ }^{30}$ Isso não é fruto de manipulação, malícia ou estratégia, mas decorre do instinto de defesa potencializado pelo peso da mudança. ${ }^{31}$

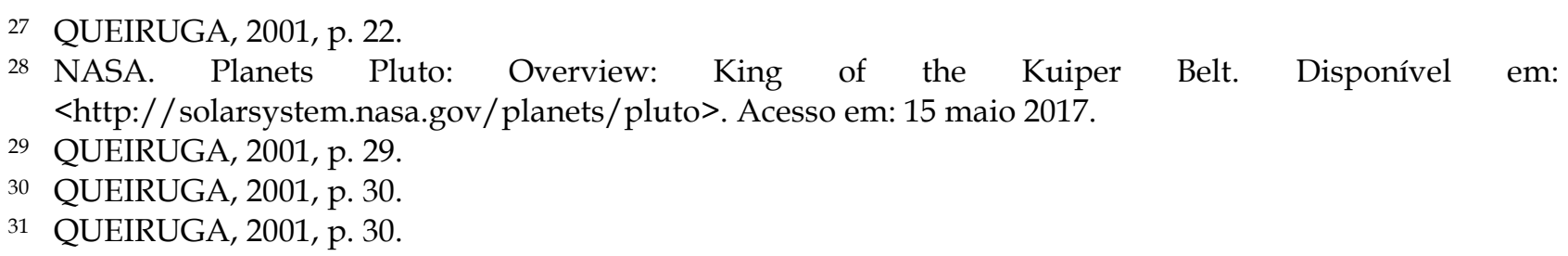




\section{Um conceito não fundamentalista da revelação}

O conceito de revelação progressiva é ponto chave da proposta apresentada por Queiruga, pois dessa forma é possível compreender que durante a elaboração de várias passagens, fica evidente que o autor expressava, na medida do possível, o entendimento que tinha do divino. Dessa forma, a limitação não está na capacidade de Deus em se fazer entender, mas sim, no ser humano de conseguir entendê-lo.

Qual a reação natural de um pai ou mãe ao ver seu bebê colocar os dedinhos na tomada? Imediatamente lançam um sonoro "não!". Por que então, ao invés de apenas uma palavra proibitiva não explicam a física que envolve o choque elétrico? Mesmo que utilizassem toda didática e recursos tecnológicos, seria possível levar o bebê a ter compreensão do fenômeno? Percebe-se claramente a impossibilidade de tal explicação, não por parte dos pais, mas por parte do bebê. Ao analisar o processo de revelação na história, Queiruga dirá que “em tais circunstâncias, não é que Deus não seja onipotente, mas sim que é impossível que essas pessoas possam entender determinadas verdade ou, mais simplesmente, interessar-se por elas". ${ }^{32}$

Queiruga sintetiza seu pensamento da seguinte maneira:

Deus, voltado com todo o seu amor sobre a humanidade, luta contra nossa ignorância e nossa pequenez, contra nossos instintos e resistências, contra nossos mal-entendidos e perversões, para ir abrindo-nos seu coração e iluminar para nós seu rosto, para manifestar-nos a profundidade de nosso ser e a esperança de nosso destino. ${ }^{33}$

E completa:

Quando realmente assumimos essa perspectiva, a própria Bíblia adquire uma nova luz e tudo se entende melhor. Suas dúvidas e obscuridades, seus avanços e vacilações são vistos agora como fruto da luta amorosa de Deus para tornar compreensível seu designo salvífico, aproveitando-se das diversas circunstâncias e valendo-se de todos os meios. ${ }^{34}$

Assim, segundo o mesmo autor, a Bíblia leva consigo a marca do seu tempo e lugar, apresenta um conhecimento progressivo de Deus e suas afirmações precisam ser lidas dentro de seu contexto, uma vez que fora dele, pode muitas vezes surpreender e até mesmo escandalizar. ${ }^{35}$ Seu nascedouro se dá no "descobrimento de Deus na vida de um

\footnotetext{
QUEIRUGA, 2001, p. 34.

QUEIRUGA, 2001, p. 34.

QUEIRUGA, 2001, p. 34.

QUEIRUGA, 2001, p. 40.
} 
povo e do progressivo aprofundamento na compreensão tanto de seu modo de relacionarse com os homens e mulheres como dos modos de conduta que procurar suscitar deles" ${ }^{36}$

A crítica bíblica, como dito anteriormente, é determinante para uma reflexão sobre a conduta de encarar a revelação, não para diminuí-la, mas trazendo à tona ainda mais suas virtudes. Portanto, para Queiruga, torna-se insustentável nos dias atuais encará-la como um "ditado" divino. O relato do dilúvio, por exemplo, uma cópia quase ipsis litteris do poema da Gilgamesh, o qual é datado de aproximadamente mil anos antes do livro do Gênesis, faria do escritor bíblico um aluno que "cola" na prova para passar de ano. ${ }^{37}$

Incontáveis exemplos podem ser transcritos para retratar que existe uma intenção no texto que perpassa sua letra. Caso contrário, a física precisaria rever seus conceitos para admitir que é o Sol quem gira ao redor da Terra, ou quem sabe, por defesa ao texto bíblico, alguns dirão que no passado, pode ter sido assim. Será então que isso descredibiliza o texto? Reduz sua relevância? Queiruga irá dizer que:

uma Bíblia "perfeita", sem as feridas do tempo, não seria a melhor prova de que se trataria de um livro "ajeitado"? Da mesma forma, seria igualmente descabida a atitude oposta, ou seja, a de pretender que tudo o que se diz na Bíblia tenha, sem mais nem menos e literalmente, validade atual; nesse caso, seria necessário continuar exterminando o inimigo com toda a sua família, ou crendo que a humanidade tem só seis mil anos e que o Sol gira ao redor da Terra. ${ }^{38}$

Estreitamente ligado ao avanço nos estudos bíblicos está o desenvolvimento tecnológico obtido no último século. Atualmente, circula uma quantidade de informações impossíveis de serem acompanhadas; semelhantemente, as mídias sociais invadiram a vida da sociedade e transformaram o modo de relacionamento entre as pessoas.

Tornou-se muito perigoso fazer qualquer julgamento a respeito de uma determinada notícia sem antes apurar a fundo sua veracidade, pois muitas vezes são falsas ou com autoria atribuída indevidamente. Portanto, devido ao acesso a incontáveis ferramentas de pesquisa, ninguém mais precisa se limitar a aceitar tudo o que recebe, basta ter o interesse de buscar por fontes confiáveis e fazer algum tipo de verificação.

Baseado nesse cenário, Queiruga apresenta a visão de que não se deve crer em tudo o que é dito. No âmbito religioso, seria o acreditar apenas "porque a "santa madre Igreja o diz", porque alguns lhe disseram, os quais, por sua vez, "disseram que Deus lhes havia dito"'" 39 Isso é muito bem ilustrado na brincadeira infantil chamada de "telefone

\footnotetext{
QUEIRUGA, 2001, p. 40.

QUEIRUGA, 2001, p. 38.

QUEIRUGA, 2001, p. 41.

39 QUEIRUGA, 2001, p. 46.
} 
sem fio", perde-se tanto a rastreabilidade do autor quanto do conteúdo original da mensagem.

Quando esse compêndio de dogmas e doutrinas são transmitidos por uma "autoridade espiritual", isso toma quase peso de lei. Entretanto, Queiruga aponta para uma reflexão sobre essa passividade, incentiva a adoção de uma postura investigativa e questionadora, a saber:

É certo que, se a Igreja não nos dissesse, muitos de nós não chegariam à fé, e que sem os grandes profetas, acima de tudo sem Jesus de Nazaré, também a própria Igreja não o saberia. No entanto, uma vez que nos foi dito, não ficamos às cegas, como crianças que devem obedecer "por que sim", "porque é a mãe que está dizendo". A palavra reveladora dirige-se à nossa vida e a nosso mundo, para desvendá-los e, sua realidade última e definitiva. Por isso, ela o faz solicitando nossa inteligência e batendo à porta de nossa liberdade; não como imposição autoritária ou alienação intelectual. Definitivamente, aceitamos a Bíblia quando ela se apresenta a nós como parteira de nossa mais radical autenticidade em sua relação com o mundo, com os demais e com Deus. ${ }^{40}$

Essencialmente para fé cristã, a Bíblia é a principal fonte que fundamenta a vida do fiel. Contudo, esta precisa trazer sentido, despertar a consciência e por sua vez impulsionar a renovação da Palavra, pois deve responder de maneira relevante às demandas que vão sendo geradas em cada novo tempo e época.

Um mínimo de sentido realista indica que, sem a Bíblia, é muito provável que o cristianismo tivesse se perdido no marasmo das crises históricas. E nossa própria experiência individual ensina-nos que o recurso à Palavra normalmente representa um meio indispensável para avivar em nós o rescaldo da presença divina, que tantas coisas tendem a ocultar e a deformar. O elemento decisivo, todavia, é que em nenhum caso se trata de uma recordação externa e distante. Trata-se de uma relação viva, na qual, aqui e agora, sou eu quem reconheço Deus presente em minha existência, acolhendo-me, apoiando-me, guiando-me, falando-me. ${ }^{41}$

É fato que a produção teológica não acompanhou a velocidade das transformações ocorridas no último século. Pelo contrário, a história da igreja se caracteriza por adotar uma postura na contramão da cultura, sem um debate de ideias. Em decorrência disso, estabeleceu-se um distanciamento entre fé, a compreensão que o homem tem de si mesmo e sua percepção de mundo. ${ }^{42}$

Conquanto, não é apenas a fé que está mudando, mas sim toda a vida. A tecnologia e a alta competitividade do capitalismo são apenas alguns exemplos de fatores

40 QUEIRUGA, 2001, p. 46.

41 QUEIRUGA, 2001, p. 48.

42 QUEIRUGA, 2001, p. 52. 
que transformaram as características da existência. Uma frase bem comum é: “Nossa, como o ano voou. Na minha infância não parecia ser assim, o ano demorava tanto para passar!". O dinamismo da vida mudou completamente os hábitos e costumes, transformou não apenas o espiritual, mas reconfigurou toda a vida humana.

Viu-se que as elaborações já feitas não conseguiam responder às novas inquietudes, mas também que as possíveis respostas alternativas ainda não haviam sido preparadas. Entre esse "já não" e esse "ainda não", delimita-se o elemento fundamental da atual situação. ${ }^{43}$

Importante pontuar a relevância existente na experiência sincera e simples que ocorre espontaneamente na vida de um fiel, simples não no sentido de simplório, mas de sem artifícios, que se realiza de maneira natural, singela, leve, que rearranja os rumos de toda uma vida. Um encontro particular com o divino, sem muitas problematizações, porém extremamente profundo, "sua carga vivencial ultrapassa as complicações do raciocínio e vai direto ao coração e à vida". ${ }^{44}$

Aqui então se estabelece um grande perigo, muitas lideranças justificam o afastamento do ensino teológico mais crítico para não complicar essa confissão espontânea e comunitária da fé. Contudo, Queiruga aponta que deve-se evitar justamente essa polarização, negar o desenvolvimento intelectual acolhendo apenas a experiência cotidiana, nem tão pouco se fechar no conhecimento racional em detrimento dos relacionamentos.

Isso não significa que o estritamente intelectual deva ser descuidado; justamente com a relativização do que é secundário, produz-se - como disse - o realce daquilo que é fundamental. De fato, uma das características importantes da teologia atual é sua "concentração" naquilo que é radical e decisivo da fé. Concentração que não é redução, mas valoração justa, distinção de níveis, hierarquização de valores. ${ }^{45}$

Fato é que cada geração precisa buscar caminhos de atualização dos textos bíblicos que permitam uma releitura viva de sua experiência original. Queiruga destaca que “a revelação nos é sempre apresentada nos moldes mentais do redator, nas preocupações e problemas de uma comunidade, nos condicionamentos culturais de uma época" ${ }^{46}$

Quando o foco está na experiência original, pode-se alterar os aspectos periféricos, mas o núcleo continua preservado. Certamente os textos bíblicos estão repletos de elementos que faziam parte do cotidiano da época, peculiaridades de seu tempo, que se lidas literalmente não farão qualquer sentido.

43 QUEIRUGA, 2001, p. 54.

44 QUEIRUGA, 2001, p. 57.

45 QUEIRUGA, 2001, p. 58.

46 QUEIRUGA, 2001, p. 61. 
É insustentável a ideia de o mundo contemporâneo ser semelhante ao dos tempos bíblicos, que não existiu todo um desenvolvimento do cristianismo ao longo dos últimos séculos, soma-se o fato que a visão ocidental a respeito da vida e do mundo é completamente diferente da palestina.

Ainda sobre os problemas decorrentes do distanciamento entre fé e pósmodernidade, a intolerância religiosa aparece sistematicamente nas situações mais corriqueiras da vida. Os casos mais graves noticiados pela mídia são incapazes de representar o quanto essa atitude está enraizada na sociedade. Para Queiruga, “a busca ecumênica, nesse sentido, é um avanço; pondo em comunhão as diversas sensibilidades cristãs, elas potencializam-se e aumente sua capacidade de sintonia" ${ }^{47}$

Será então que existem caminhos para uma reinterpretação da Palavra sem se afastar do genuíno da experiência cristã? É possível expressá-la de forma comprometida e dentro dos contextos atuais da pós-modernidade, sem maquiagem, mas com uma postura que encare de frente, com seriedade e responsabilidade as dificuldades impostas pelo tempo atual? Para responder essas perguntas e sintetizar o eixo do seu pensamento, Queiruga apresenta os seguintes vetores para sua proposição:

Inicialmente, propõe 'Deus como afirmação criadora'. A reflexão do autor está preocupada com a recuperação de uma imagem positiva do Deus cristão frente às problemáticas impostas pela pós-modernidade. ${ }^{48}$

Na sequência, apresenta 'Deus como paternidade salvadora', posiciona o ser humano dentro da dinâmica de uma revelação em processo e faz das lutas diárias instrumentos a serviço da realização da obra criadora / salvadora de Deus. ${ }^{49}$

Por fim, anuncia 'Deus como encarnação realizadora' onde estabelece uma relação viva com o homem na história, na qual cabe a renovação e atualização da Palavra, tendo a Encarnação como ponto central. ${ }^{50}$

Pode-se dizer que Queiruga consolida seu raciocínio com as seguintes palavras:

Em face disso, é necessário ter a coragem de deixar-se interrogar até os alicerces, para confessar nosso credo a partir do despojamento de toda ilusão infantil. Crer em Deus Pai, mas no Pai de Jesus, que não exime da tentação, nem da cruz; que exige a confiança da criança, mas não a partir da onipotência do desejo e sim da responsabilidade da entrega até a morte. Crer em um perdão que não oculta o pecado nem o dissimula na fobia, na

7 QUEIRUGA, 2001, p. 63.

8 QUEIRUGA, 2001, p. 67.

49 QUEIRUGA, 2001, p. 68.

50 QUEIRUGA, 2001, p. 69. 
angústia ou no escrúpulo, mas confia na força transformadora do amor, que é capaz de transformar-nos em uma "nova criatura" ${ }^{51}$

\section{Considerações finais}

Em face às dificuldades e inseguranças apresentadas pela vida, a hermenêutica fundamentalista torna-se extremamente sedutora, pois propõe certezas e "verdades inquestionáveis" ao invés de reflexão e diálogo. Dentro de uma comunidade de fé, isso tende a sucumbir o desenvolvimento da razão e sufocar as perguntas que inquietam os corações. Essa abordagem cria barreiras de difícil transposição para o cidadão comum, principalmente por sua conjuntura, posto que as interpretações são anunciadas como retrato da vontade divina.

Importante estabelecer que o fato de uma não aproximação para com as Escrituras, mediante a leitura literal dos textos, não caracteriza uma atitude de profanação, muito pelo contrário, a abordagem literalista reduz a riqueza ali contida a um único entendimento que pretende ser detentor da verdade. A profundidade da experiência original perpassa o próprio texto, está para além dele.

O retorno à tradição histórica terá sempre uma função primordial no contexto religioso. Impossível negar que esta foi desenvolvida dentro de um lugar vivencial totalmente diferente do atual e para atender a demandas da época. Contudo, o fiel deve apropriar-se da experiência original e torná-la viva, sem que isso represente uma mera repetição.

Ler a Bíblia mediante uma perspectiva histórico-literária é uma excelente ferramenta que ajuda o leitor a perceber o momento e a finalidade para qual o texto foi elaborado. Admitir que a Bíblia não tem todas as respostas prontas para os problemas da vida é um primeiro passo na compreensão de sua formação. Nesse sentido, a reflexão apresentada por Queiruga orienta como fazê-la de maneira responsável.

Em outras palavras, não é possível continuar negligenciando a interação com a pós-modernidade. Esta, por sua vez, clama por uma mensagem que traga sentido a sua existência, sentido esse que pode ter como guia os textos sagrados, quando estes estiverem livres para iluminar a escuridão que assola os corações aflitos.

Impossível não mencionar Rubem Alves e seu clássico $A$ menina e o pássaro encantado ${ }^{52}$ (2010) o qual exemplifica brilhantemente a problemática abordada até aqui, pois o desejo de ter o pássaro encantado ao seu lado foi resolvido colocando-o numa gaiola. Entretanto, com o tempo, este perdeu o brilho, a alegria e as cores. De modo

1 QUEIRUGA, 2001, p. 68.

52 ALVES, 1975. 
semelhante, ocorre com a Palavra quando seus textos são engessados e sua interpretação restrita a um único entendimento.

Todavia, pode-se afirmar que somente com humildade será possível realizar a árdua e complexa tarefa de conjugar as demandas contemporâneas com a histórica cultura cristã. Mediante a mensagem de amor defendida até a morte por Jesus, deve-se repudiar qualquer tipo de violência e intolerância, pois é imprescindível que o processo seja pautado num debate respeitoso de ideias. ${ }^{53}$

Cabe à teologia atual enfrentar o desafio de utilizar os recursos hermenêuticos disponíveis e fazer a ponte entre a riqueza inesgotável da Palavra com as perguntas e anseios atuais. Este é um trabalho necessário e que precisa ser realizado com seriedade, sensibilidade, profundidade, comprometimento com o próximo e, acima de tudo, com o Deus Pai apresentado por Jesus. Caso contrário, o futuro será o retrato dos versos eternizados por Elis Regina:

Você pode até dizer que eu tô por fora

Ou então que eu tô inventando,

mas é você que é mal passado e que não vê

que o novo sempre vem [...]

Minha dor é perceber que apesar de termos feito

Tudo o que fizemos, ainda somos os mesmos

e vivemos como os nossos pais. ${ }^{54}$

\section{Referências}

ALVES, R. O Enigma da Religião. Petrópolis: Vozes, 1975.

ARENS, E. A Bíblia sem mitos: uma introdução crítica. São Paulo: Paulus, 2007.

BALEEIRO, C. A. S. A Dinâmica dos Fundamentalismos: modernidade e tradição. In: SOUZA, Sandra Duarte de. (Org.). Fundamentalismos religiosos contemporâneos. São Paulo: Fonte, 2013.

BOFF, L. Fundamentalismo, terrorismo, religião e paz: desafio para o século XXI. Petrópolis: Vozes, 2009.

DREHER, M. N. Fundamentalismo. São Leopoldo: Sinodal, 2006.

LIMA, M. L. C. Fundamentalismo: Escritura e Teologia entre fé e razão. Atualidade Teológica, ano XIII, n. 33, set./dez. 2009.

NASA. Planets Pluto: Overview: King of the Kuiper Belt. Disponível em: <http:// solarsystem.nasa.gov/ planets/pluto>. Acesso em: 15 maio 2017.

53 BOFF, 2009, p.64. A paz se constrói com meios pacíficos como o encontro fraterno, o diálogo, a mútua acolhida e o respeito das diferenças, impedindo que estas diferenças sejam entendidas como desigualdades.

54 Belchior. Trecho da música "Como Nossos Pais". 
PANASIEWICZ, R. Fundamentalismo Religioso: história e presença no cristianismo. In: X Simpósio da Associação Brasileira da História das Religiões: Migrações e Imigrações das Religiões, 2008.

QUEIRUGA, A. T. Do Terror de Isaac ao Abbá de Jesus. São Paulo: Paulinas, 2001.

VECCHIA, F. Dalla. Método histórico-crítico. In: VV.AA. Dicionário teológico enciclopédico. São Paulo: Loyola, 2003. 